CZASOPISMO INŻYNIERII LA¿DOWEJ, ŚRODOWISKA I ARCHITEKTURY JOURNAL OF CIVIL ENGINEERING, ENVIRONMENT AND ARCHITECTURE

JCEEA, t. XXXIII, z. 63 (2/I/16), kwiecień-czerwiec 2016, s. 121-128

\author{
Sabina KSIĄŻEK ${ }^{1}$ \\ Małgorzata KIDA ${ }^{2}$ \\ Piotr KOSZELNIK ${ }^{3}$
}

\title{
BENZOTRIAZOLE - WYSTĘPOWANIE I TRWAŁOŚĆ W ŚRODOWISKU
}

\begin{abstract}
Praca zawiera przegląd literatury dotyczący właściwości i występowania benzotriazoli (BTR) w różnych komponentach środowiska. Szczególną uwagę zwrócono na problem zagrożenia dla jakości środowiska wynikającego z obecności i trwałości w środowisku związków z tej grupy i ich pochodnych. Właściwości benzotriazoli sprawiają, że są one powszechnie wykorzystywane w wielu gałęziach przemysłu. Stosuje się je między innymi jako inhibitory korozji, stabilizatory światła ultrafioletowego do tworzyw sztucznych oraz jako środki rozjaśniające w przemyśle metalowym. Ponadto znajdują zastosowanie w produkcji kosmetyków, detergentów, leków, materiałów budowlanych i części samochodowych. Istnieją jednak ograniczone dane dotyczące losu benzotriazoli, które są uwalniane do środowiska. Ze względu na odporność benzotriazoli na utlenianie w warunkach otoczenia i na promieniowanie UV, mogą być obecne w środowisku przez bardzo długi okres czasu. Stabilność benzotriazoli skutkuje tym, że nie są one usuwane ze ścieków przy zastosowaniu konwencjonalnych metod z zadowalającą wydajnością. Dodatkowo, odporność na biodegradację i właściwości fizyko-chemiczne benzotriazoli powodują, że są obecne we wszystkich komponentach środowiska. Zostały wykryte w ściekach, wodach powierzchniowych, osadach dennych, glebie, powietrzu, a nawet w kurzu domowym i organizmach żywych np. w rybach. Potwierdzone negatywne oddziaływanie na organizmy żywe, wynikające w szczególności z ich aktywności estrogenowej, mutagenności, toksyczności i rakotwórczości wymaga opracowania skutecznej metody eliminacji BTR.
\end{abstract}

Słowa kluczowe: benzotriazole, mikrozanieczyszczenia, związki endokrynnie czynne, degradacja

\footnotetext{
${ }^{1}$ Autor do korespondencji/corresponding author: Sabina Książek Politechnika Rzeszowska, Zakład Inżynierii i Chemii Środowiska, Wydział Budownictwa, Inżynierii Środowiska i Architektury, al. Powstańców Warszawy 12, 35-959 Rzeszów, tel. + 48 (017) 865 1065, + 48 (017) 865 2407, e-mail: sabina_ksiazek@outlook.com

2 Małgorzata Kida, Politechnika Rzeszowska

${ }^{3}$ Piotr Koszelnik, Politechnika Rzeszowska
} 


\section{Wprowadzenie}

Benzotriazole należą do nowo pojawiających się zanieczyszczeń środowiska wodnego, które zaliczane są do związków endokrynnie czynnych. Związki $\mathrm{z}$ grupy benzotriazoli oraz ich pochodne są szeroko wykorzystywane $\mathrm{w}$ wielu gałęziach przemysłu. Ze względu na ich właściwości, znalazły zastosowanie w produkcji opon i gumy, jako inhibitory korozji, w produkcji środków biobójczych, detergentów oraz leków. Ponadto, stosowane są jako stabilizatory UV w plastikach, farbach, foliach i powłokach oraz w systemach chłodniczych (grzejniki samochodowe i kotły handlowe), jak również jako dodatki do produktów naftowych, takich jak płyny hydrauliczne i środki smarujące. Związki te były również wykorzystywane w przemyśle fotograficznym [2].

Ich odporność na biodegradację i utlenianie w warunkach naturalnych powoduje, że benzotriazole mogą utrzymywać się w środowisku przez bardzo długi czas $[6,12]$. Dodatkowo badania toksykologiczne wykazały, że związki te są niebezpieczne dla roślin, toksyczne i mutagenne dla niektórych mikroorganizmów. Natomiast 1H-benzotriazol wykazuje właściwości rakotwórcze dla człowieka $[4,11,17]$. Obecność benzotriazoli i innych mikrozanieczyszczeń w wodach powierzchniowych i w wodzie pitnej świadczy o tym, że konwencjonalne metody oczyszczania wody i ścieków są niewystarczające i aktualne pozostają badania nad opracowaniem skutecznej metody eliminowania związków, które często w małych ilościach są bardzo niebezpieczne i toksyczne dla środowiska.

Celem artykułu jest omówienie właściwości, występowania benzotriazoli w różnych komponentach środowiska oraz metod eliminowania ich z roztworów wodnych na podstawie przeglądu literatury.

\section{Właściwości chemiczne i fizyczne benzotriazoli}

Benzotriazole (BTR) powstają w wyniku połączenia się triazolu z cząsteczką benzenu. Triazol jest pięcioczłonowym związkiem heterocyklicznym zawierającym trzy atomy azotu i parę sąsiadujących atomów węgla. Na rysunku 1 zaprezentowano dwa najprostsze izomery triazolu [5].<smiles>c1c[nH]nn1</smiles><smiles>c1cn[nH]c1</smiles>

Rys. 1. Struktura $1 \mathrm{H}$-triazolu (a) i 2H-triazolu (b), opracowano na podstawie [2]

Fig. 1. Structure of the $1 \mathrm{H}$-triazole (a) and $2 \mathrm{H}$-triazole (b), based on [2] 
Przedstawicielem benzotriazoli jest związek 1H-benzotriazol. Struktura tego związku została przedstawiona na rys. 2 [7].

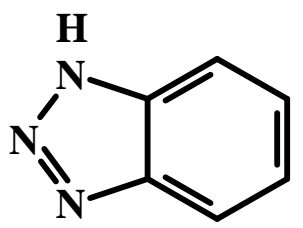

Rys. 2. 1H-Benzotriazol, opracowano na podstawie [2]

Fig. 2. 1H-Benzotriazole, based on [2]

Od momentu odkrycia podstawowej struktury BTR, metody syntezy tych związków szybko ewoluowały. Wiele z tych metod opiera się na reakcji diazowania. W skrócie, BTR mogą być wytwarzane w reakcji fenylenodiaminy, azotynu sodowego i kwasu octowego, poprzez diazowanie jednej z grup aminowych [19]. Struktura benzotriazolu jest podatna na szereg reakcji i można otrzymać wiele pochodnych, jednakże w większości przypadków grupa triazolowa pozostaje niezmieniona [5].

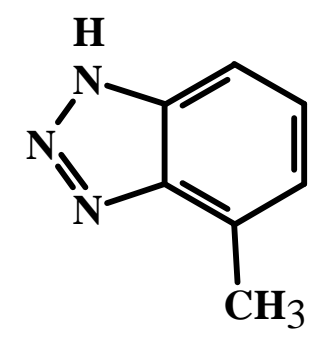

Rys. 3. 5-metylobenzotriazol, opracowano na podstawie [2]

Fig. 3. 5-methylbenzotriazole, based on [2]

BTR to polarne związki, które stosunkowo dobrze rozpuszczają się w wodzie. Przykładowo, rozpuszczalność 1H-benzotriazolu (1H-BTR) wynosi 19,8 g/l, a 5-metylobenzotriazolu (5Me-BTR) (rys. 3) 3,1 g/l. Natomiast współczynniki podziału oktanol-woda (log Kow) wynoszą odpowiednio 1,4 i 1,7 dla 1H-BTR i 5Me-BTR (tab. 1 ) [1].

Tabela 1. Wybrane właściwości 1H-BTR i 5Me-BTR, opracowano na podstawie [1] Table 1. Selected properties of 1H-BTR and 5-methyl-BTR, based on [1]

\begin{tabular}{|c|c|c|}
\hline Parametry & 1H-BTR & 5Me-BTR \\
\hline $\mathbf{p K} \mathbf{K}_{\mathbf{a}}$ & 8,4 & - \\
\hline $\log \mathbf{K}_{\mathbf{o w}}$ & 1,4 & 1,7 \\
\hline Rozpuszczalność $\mathbf{w}$ wodzie $[\mathbf{g} / \mathbf{l}]^{\mid}$ & 19,8 & 3,1 \\
\hline
\end{tabular}


Stabilność jest kluczową cechą większości wykorzystywanych w przemyśle benzotriazoli. BTR tworzą bardzo stabilne kompleksy z wieloma metalami. Kompleks BTR z metalem tworzy warstwę pasywną na powierzchni metalowej, zapobiegając reakcji powierzchniowej, czyli korozji. Właściwości antykorozyjne posiadają cząsteczki zawierające atom wodoru w pozycji 1 oraz benzotriazole z grupą metylową, na przykład 4Me-BTR i 5Me-BTR [18].

W przypadku stabilizacji na promieniowanie UV stosowane są natomiast BTR z grupą fenylową w pozycji 2 (rys. 4). Są one zdolne do absorbowania światła UV w zakresie $300-400 \mathrm{~nm}$. Mechanizm stabilizacji polega na przekształceniu pochłoniętej energii świetlnej na ciepło, która jest w istocie odwracalną reakcją przeniesienia protonu. Wydajność absorpcji zależy od rodzaju i ilości użytego benzotriazolu oraz od składu materiału [2].

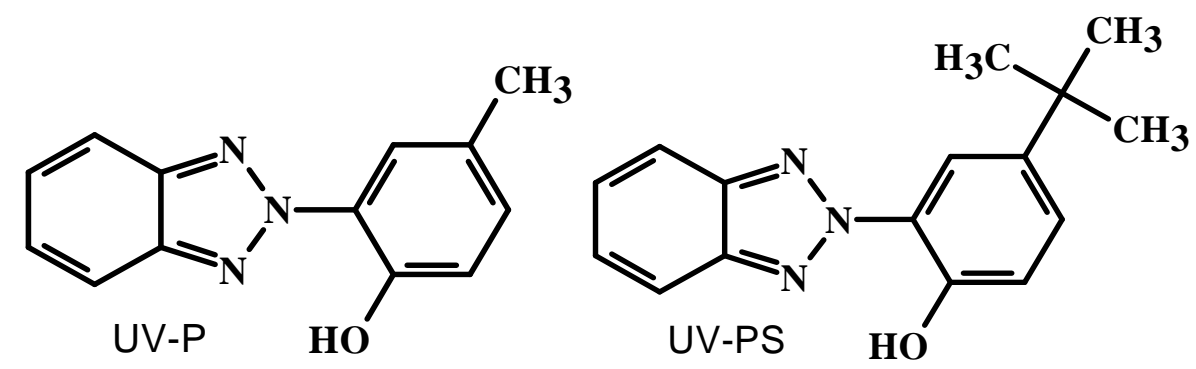

Rys. 4. Przykłady benzotriazoli zdolnych do absorbowania promieniowania UV, opracowano na podstawie [2]

Fig. 4. Examples of the benzotriazoles capable of absorbing UV radiation, based on [2]

\section{Występowanie benzotriazoli w środowisku}

Szerokie zastosowanie benzotriazoli doprowadziło do ich rozpowszechnienia się $\mathrm{w}$ środowisku. $\mathrm{Z}$ kolei stopniowy wzrost poziomu zanieczyszczenia środowiska tymi substancjami spowodował ich akumulację w organizmach żywych, jednocześnie tworząc zagrożenie dla ich zdrowia, przede wszystkim ze względu na właściwości kancerogenne. Człowiek jest narażony na benzotriazole pochodzące z różnych źródeł emisji, dominującą rolę odgrywają środki czystości oraz leki. Na przykład, związki te stanowią jeden ze składników tabletek przeznaczonych do mycia naczyń w zmywarkach. Janna i in. (2011) oraz Vetter i in. (2013) w swoich publikacjach podają stężenia benzotriazoli w detergentach do mycia naczyń stosowanych w Wielkiej Brytanii i Niemczech. Zawartość BTR w tabletkach do zmywarek w Niemczech wahała się od 2 do $66 \mathrm{mg}$, podczas gdy podobne badania proszków i tabletek w Wielkiej Brytanii wykazały nieco niższe stężenia, na poziomie od 1,45 do $28 \mathrm{mg}$ BTR w jednej tabletce. W wyniku tego, zawartość związków w ściekach dopływających do wybranych trzech oczysz- 
czalni ścieków w Niemczech obserwowano w zakresie od 17 do $44 \mu \mathrm{g} / \mathrm{l}$ dla 1H-benzotriazolu oraz od 1,1 do 4,9 $\mu \mathrm{g} / \mathrm{l}$ dla metylo-1H-benzotriazolu (TT) [16]. Ponadto, substancje te mogą migrować pomiędzy różnymi elementami środowiska. W USA, w wodach powierzchniowych stwierdzono obecność 1H-BTR w $45 \%$ badanych próbkach, co wskazuje, że związki te są powszechne w wodach naturalnych, a ich głównym źródłem są ścieki oczyszczone. Natomiast na terenie Unii Europejskiej w 100 wybranych rzekach wykryto 1H-BTR i TT odpowiednio w 94\% i $81 \%$ analizowanych próbkach, na poziomie $8 \mu \mathrm{g} / \mathrm{l}$ dla 1H-BTR i $19 \mu \mathrm{g} / \mathrm{l}$ dla TT [10]. Substancje te łatwo adsorbują się na cząstkach stałych, w USA w osadach dennych rzeki Pawtuxet związki z grupy BTR wykryto w granicach 4300-5200 mg/kg [15], w Chinach w rzece Songhau od 0,31 do $7,12 \mu \mathrm{g} / \mathrm{kg}$ [14]. Natomiast w Hiszpanii w kurzu domowym zawartość tych związków wahała się w przedziale $22-657 \mu \mathrm{g} / \mathrm{kg}$ [3]. W glebie zazwyczaj BTR bada się w okolicach dróg, stref przemysłowych, na terenach miejskich w Sztokholmie wartość ta wyniosła 3,7 $\mu \mathrm{g} / \mathrm{g}$ dla UV $360 \mathrm{~nm}[2,9]$.

Niestety w literaturze jest mało danych na temat toksyczności poszczególnych związków z grupy BTR na organizmy żywe. Stopień narażenia na benzotriazole w głównej mierze jest uzależniony od ich stężenia. Granica tolerancji dla ryb słodkowodnych to wartość 27,5 ppm w czasie ekspozycji równej 48 godzin i 25 ppm w ciągu 96 godzin. Przy czym śmiertelność jest znacznie wyższa po 96 godzinach ekspozycji na BTR [22].

\section{Możliwości usuwania BTR}

Benzotriazole są odporne na biodegradację, chlorowanie oraz konwencjonalne oczyszczanie ścieków [16]. Mogą być natomiast usuwane w procesie ozonowania i przy zastosowaniu zaawansowanego utleniania [13]. Szybki rozkład benzotriazoli zaobserwowano w reakcji z odczynnikiem Fentona [22]. BTR ulegają również degradacji fotochemicznej, jednakże wymagane są wysokie dawki promieniowania UV i produkty pośrednie mogą mieć formę bardziej toksyczną. Przykładowo, 1H-BTR może być usuwany przez promieniowanie UV w środowisku o $\mathrm{pH}$ poniżej 7. Wydajność tego procesu jest znikoma, a produktami reakcji są trująca anilina i fenazyna [9]. Adsorpcja na węglu aktywnym okazała się być skuteczna $\mathrm{w}$ eliminacji benzotriazoli zawierających grupy metylowe [16]. W procesie ozonowania możliwe jest usuwanie benzotriazoli o właściwościach antykorozyjnych. Według zespołu badawczego Weissa i in. (2006) wydajność ta może wynosić nawet 99\%, ale mechanizm tej reakcji nie został jeszcze dokładnie poznany i nieznane są produkty końcowe ozonowania benzotriazoli [13]. Tabela 2 przedstawia wydajność usuwania BTR w przykładowych procesach. 
Tabela 2. Eliminacja BTR, opracowano na podstawie [9]

Table 2. Elimination of BTRs, based on [9]

\begin{tabular}{|c|c|c|}
\hline & Związek chemiczny & Wydajność eliminacji [\%] \\
\hline \multirow{2}{*}{$\begin{array}{c}\text { Oczyszczalnia ścieków } \\
\text { (Berlin) }\end{array}$} & $1 \mathrm{H}-\mathrm{BTR}$ & 37 \\
\cline { 2 - 3 } & $4 \mathrm{Me}-\mathrm{BTR}$ & 0 \\
\cline { 2 - 3 } & $5 \mathrm{Me}-\mathrm{BTR}$ & 11 \\
\hline \multirow{2}{*}{$\begin{array}{c}\text { Oczyszczalnia ścieków } \\
\text { (Europa) }\end{array}$} & $1 \mathrm{H}-\mathrm{BTR}$ & 34,5 \\
\cline { 2 - 3 } $\begin{array}{c}\text { Oczyszczalnia ścieków } \\
\text { (Szwajcaria) }\end{array}$ & $\mathrm{TT}_{\mathrm{S}}$ & 11,3 \\
\cline { 2 - 3 } & $1 \mathrm{H}-\mathrm{BTR}$ & 22,6 \\
\hline \multirow{3}{*}{\begin{tabular}{c} 
Bioreaktor Membranowy \\
\cline { 2 - 3 }
\end{tabular}} & $1 \mathrm{HT}-\mathrm{BTR}$ & 64,4 \\
\cline { 2 - 3 } & $4 \mathrm{Me}-\mathrm{BTR}$ & 14 \\
\hline Ozonowanie & $5 \mathrm{Me}-\mathrm{BTR}$ & 61 \\
\hline
\end{tabular}

\section{Podsumowanie}

Benzotriazole to grupa związków, wśród których liczne wykazują właściwości mutagenne i kancerogenne. Dodatkowo, BTR wykazują potencjalną zdolność do biokumulacji. W zależności od matrycy są wykrywane w szerokich granicach stężeń. BTR są trwałe w środowisku, a długotrwałe narażenie na ich działanie nawet $\mathrm{w}$ małych stężeniach może prowadzić do poważnych skutków zdrowotnych. W konsekwencji tego, ważnym aspektem związanym $\mathrm{z}$ obecnością tych związków są cykliczne pomiary ich stężeń i badania wpływu na zdrowie organizmów żywych. Znajomość trwałości substancji organicznej i jej produktów rozkładu ma również ogromne znaczenie dla wiarygodności wyników oznaczeń różnego rodzaju analitów w poszczególnych próbkach środowiskowych oraz w celu opracowania skutecznej metody ich usuwania. Ze względu na potencjalnie wysoką odporność na degradację substancje te mogą być obecne w środowisku przez bardzo długi czas.

\section{Literatura}

[1] Breedveld G.D., Roseth R., Hem L., Sparrevik M. Triazoles in the terrestrial Environment. NGI report no. 20001103-1, Oslo 2002.

[2] Cantwell M.G., Sullivan J.C., Burgess R.M. Benzotriazoles: History, Environmental Distribution, and Potential Ecological Effects. Comprehensive Analytical Chemistry, Vol. 67. Published by Elsevier B.V. 2015.

[3] Carpinteiro I., Abuin B., Rodriguez I., Ramil M., Cela R. Journal of Chromatography A, 1217 (24), 2010, pp. 3729-3735.

[4] Casado J., Nescatelli R., Rodriguez I., Ramil M., Marini F., Cela R. Determination of benzotriazoles in water samples by concurrent derivatization-dispersive liquid- 
liquid microextraction followed by gas chromatography-mass spectrometry. Journal of Chromatography A, 1336, 2014, pp. 1-9.

[5] Davis L.N., Santodonato J., Howard P., Saxena J. Investigation of Selected Potential Environmental Contaminants: Benzotriazoles. Final Report Prepared for Office of Toxic Substances, US Environmental Protection Agency, Washington, DC, 1977.

[6] Durjava M.K., Kolar B., Arnus L., Papa E., Kovarich S., Sahlin U., Peijnenburg W. Experimental Assessment of the Environmental Fate and Effects of Triazoles and Benzotriazole. ATLA 41, 2013, pp. 65-75.

[7] Hart D.S., Davis L.C., Erickson L.E., Callender T.M. Sorption and partitioning parameters of benzotriazole compounds. J Microc 77, 2004, pp. 9-17.

[8] Janna H., Scrimshaw M.D., Williams R.J., Churchley J., Sumpter J.P. From dishwasher to tap? Xenobiotic substances benzotriazole and tolyltriazole in the environment. Environmental Science and Technology, 45 (9), 2011, pp. 3858 - 3864.

[9] Kiss A. System studies on 1H-Benzotriazol and Tolyltriazoles in river water and wastewater: Sources, fate and risks. Osnabrück, 2012.

[10]Loos R., Gawlik B.M., Locoro G., Rimaviciute E., Contini S., Bidoglio G. EU-wide survey of polar organic persistent pollutants in European river waters. Environmental Pollution, 157 (2), 2009, pp. 561-568.

[11] Mazioti A.A., Stasinakisa A. S., Gatidoua G., Thomaidisb N.S., Andersen H.R. Sorption and biodegradation of selected benzotriazoles and hydroxybenzothiazole in activated sludge and estimation of their fate during wastewater treatment. Chemosphere, 131, 2015, pp. 117-123.

[12] Matamoros V., Jover E., Bayona J.M. Occurrence and fate of benzothiazoles and benzotriazoles in constructed wetlands. Water Science \& Technology-WST, 61, (1), 2010, pp. 191-198.

[13] Mawhinney D.B., Vanderford B.J., Snyder S. Transformation of 1H-benzotriazole by ozone in aqueous solution. Environmental Science and Technology, 46 (13), 2012, pp. 7102-7111.

[14] Nakata H., Murata S., Filatreau J. Occurrence and Concentrations of Benzotriazole UV Stabilizers in Marine Organisms and Sediments from the Ariake Sea, Japan. Environmental Science and Technology, 43 (18), 2009, pp. 6920-6926.

[15]Reddy C.M., Quinn J.G., King J.W. Free and bound benzotriazoles in marine and freshwater sediments. Environmental Science and Technology, 34 (6), 2000, pp. 973-979.

[16]Reemtsma T.H., Miehe U., Duennbier U., Jekel M. Polar pollutants in municipal wastewater and the water cycle: occurrence and removal of benzotriazoles. Water Research, 44 (2), 2010, pp. 596-604.

[17] Roshani B., McMasterb I., Rezaeib E., Soltan J. Catalytic ozonation of benzotriazole over alumina supported transition metal oxide catalysts in water. Separation and $\mathrm{Pu}-$ rification Technology, 135, 2014, pp. 158-164.

[18] Sease C., Studies in Conservation 23 (2) (1978) 76-85.

[19] Smiley R.A. Phenylene- and Toluenediamines, Ullmann's Encyclopedia of Industrial Chemistry, sixth ed., 26, 2002, pp. 617-622. http://dx.doi.org/10.1002/14356007.a19_405, [dostęp: 10 września 2015 r.]. 
[20] Vetter W., Lorenz J. Determination of benzotriazoles in dishwasher tabs from Germany and estimation of the discharge into German waters. Environmental Science Pollution Research, 20, 2013, pp. 4435-4440.

[21] Weiss S., Jakobs J., Reemtsma T. Discharge of three benzotriazole corrosion inhibitors with municipal wastewater and improvements by membrane bioreactor treatment and ozonation. Environmental Science and Technology, 40 (23), 2006, pp. 7193-7199.

[22] Wu X.N., Chou D., Lupher L.C. Benzotriazoles: toxicity and biodegradation. Snow Bird Conference on Hazardous Waste Research, 1998, pp. 374-382.

\section{BENZOTRIAZOLES - PROPERTIES AND STABILITY IN THE ENVIRONMENT}

\section{S u m m a r y}

The work includes a review of the literature concerning the characteristics and the occurrence of benzotriazoles (BTR) in various environmental components. Particular attention was paid to the problem of risks to the quality of the environment resulting in the presence and persistence in the environment of compounds from this group and their derivatives. Properties of benzotriazoles make them widely used in many industries. They are used i.a. as corrosion inhibitors, ultraviolet light stabilizers for plastics and as brightening agents in metal industry. In addition, they are used in the production of cosmetics, detergents, medicines, building materials and auto parts. However, there is limited data on the fate of benzotriazoles that are released into the environment. Because of the benzotriazole resistance to oxidation at ambient and UV radiation they can be present in the environment for a long period of time. Stability of benzotriazoles effect that they are not removed from the waste water by conventional methods with satisfactory yields. Additionally, resistance to biodegradation and physicochemical properties of the benzotriazoles cause their presence in all components of the environment. They were detected in wastewater, surface water, sediments, soil, air, and even in house dust and in living organisms, e.g. in fish. Confirmed negative impact on living organisms, caused in particular by their estrogenic activity, mutagenicity, toxicity and carcinogenicity results in need to develop effective methods of elimination the BTRs.

Keywords: benzotriazoles, micro-pollutants, endocrine-active compounds, degradation

Przestano do redakcji: $30.08 .2015 r$.

Przyjęto do druku: 1.03.2016 r.

DOI: $10.7862 / \mathrm{rb} .2016 .115$ 